\title{
Carbon quantum dots-stabilized Pickering emulsion to prepare NIR light-responsive PLGA drug delivery system
}

\author{
Zhou, Tongchang; Huang, Zheng; Wan, Feng; Sun, Yi
}

Published in:

Materials Today Communications

Link to article, DOI:

10.1016/j.mtcomm.2020.100951

Publication date:

2020

Document Version

Peer reviewed version

Link back to DTU Orbit

Citation (APA):

Zhou, T., Huang, Z., Wan, F., \& Sun, Y. (2020). Carbon quantum dots-stabilized Pickering emulsion to prepare NIR light-responsive PLGA drug delivery system. Materials Today Communications, 23, [100951]. https://doi.org/10.1016/j.mtcomm.2020.100951

\section{General rights}

Copyright and moral rights for the publications made accessible in the public portal are retained by the authors and/or other copyright owners and it is a condition of accessing publications that users recognise and abide by the legal requirements associated with these rights.

- Users may download and print one copy of any publication from the public portal for the purpose of private study or research.

- You may not further distribute the material or use it for any profit-making activity or commercial gain

- You may freely distribute the URL identifying the publication in the public portal 


\title{
Cite this: DOI:
}

\section{Carbon quantum dots-stabilized Pickering emulsion to prepare NIR light-responsive PLGA drug delivery system}

\author{
Tongchang Zhou ${ }^{\mathrm{a}}$, Zheng Huang ${ }^{\mathrm{b}}$, Feng Wan*b and Yi Sun*a \\ Received (in XXX, XXX) Xth XXXXXXXXX 200X, Accepted Xth XXXXXXXXX 200X \\ ${ }_{5}$ DOI:
}

A new strategy to prepare NIR light-responsive Poly-lactideco-glycolide (PLGA) drug delivery systems via carbon quantum dots-stabilized Pickering emulsion polymerization was developed. We successfully fabricated oil-in-water single 10 emulsion and water-in-oil-in-water double emulsion for loading hydrophobic and hydrophilic drugs, respectively.

Nanoparticle-based drug delivery systems (DDSs) have showed great potential in variety of medical applitions. Among them, poly (lactic-co-glycolic acid) (PLGA, a polyester-based polymer 15 approved by the US FDA and European Medicine Agency (EMA) for parenteral administration), have received much attention because of their good biocompatible and biodegradable properties. 1-3 In particular, PLGA has been extensively studied for the development of carriers for delivery of small molecule drugs, 20 proteins and other macromolecules. ${ }^{4-6}$ Emulsion/evaporation techniques are traditionally employed to prepare PLGA nanoparticles. Surfactants are frequently used as stabilizing agents to reduce surface tension. However, it is difficult to remove the surfactants completely, and the residual surfactants 25 may cause allergy-like reactions and carcinogenicity. ${ }^{7}$ Therefore, a new surfactant-free synthesis method is needed.

Meanwhile, in order to achieve controlled drug release at site of action, stimuli-responsive DDSs have emerged. Compared to those relying on internal stimuli (e.g. $\mathrm{pH}$ and thermal), external 30 stimuli-triggeed DDS such as light-responsive DDS offer many advantages due to the ease of handling and precise control of the time and location of treatment. ${ }^{8-10}$ Therefore, much research effort has been devoted to the development of release systems using light-responsive nanoparticles. One typical example was ${ }_{35}$ PLGA-based polymers containing pendant nucleophiles protected with a photocleavable o-nitrobenzyl (ONB) group, which degraded in response to UV light. ${ }^{11}$ However, UV/visible light has limited applications due to the inadequate tissue penetration. As near-infrared (NIR) light has no such limitation, NIR light40 responsive nanocarriers are more appropirate for in vivo applications. ${ }^{12,13}$ Different materials have been reported to have absorption at NIR region ${ }^{14}$, such as gold nanomaterials, 15 metallicoxides/sulfides, ${ }^{16}$ etc. However, the potential toxicity has hindered their use in DDS.

45 Herein, we reported a new surfactant-free stratgey to prepare PLGA nanoparticles using carbon quantum dots (CQD)-stabilized Pickering emulsion method. Pickering emulsion is a kind of emulsion stabilized by solid particles instead of surfactant which is located at oil-water interface. It is more stable against 50 coalescence. A vast range of solid particles such as silica nanoparticle, magnetic particle, graphene oxide and even bacteria have been used to stabilize Pickering emulsion. ${ }^{17,18}$ Therefore, synthezing PLGA-based DDS by Pickering emulsion would provide a solution to avoid the side effects caused by surfactants. ${ }_{55}$ CQDs is a class of fluorescent carbon nanoparticles with size less than $10 \mathrm{~nm} .{ }^{19,20}$ They posess tunable fluorescence properties and can have strong absorption at NIR region. Moreover, the hydrophobicity of the CQDs could be controlled by appropriate surface modification. Compared with other inorganic nano60 materials, CQDs are non-toxic and highly biocompatible, which make them suitable for use in biomedical areas. ${ }^{21-24}$ Despite these advantages, CQD-stablized Pickering emulsion has seldom been reported.

In this work, for the first time, amphiphilic red carbon dots 65 (RCDs) with both hydrophilic and hydrophobic properties were successfully synthesized. They were applied as stablizer to prepare NIR-triggered PLGA DDS system using the new Pickering emulsion method. The functional groups and surface properties of RCDs offer the ability to load both hydrophobic and 70 hydrophilic drugs with high loading efficiency. Moreover, the photothermal property of RCDs enables the NIR-triggered drug release, which would greatly facilitate to achieve the targeting drug release at the site of action.

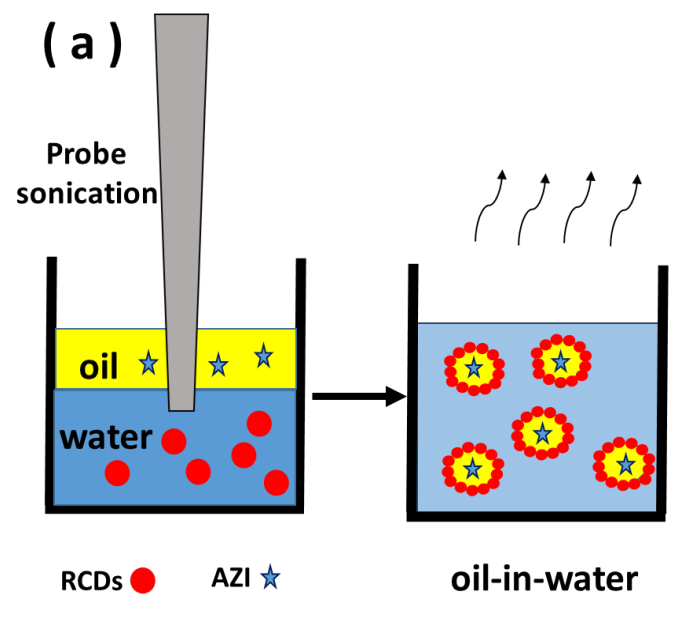




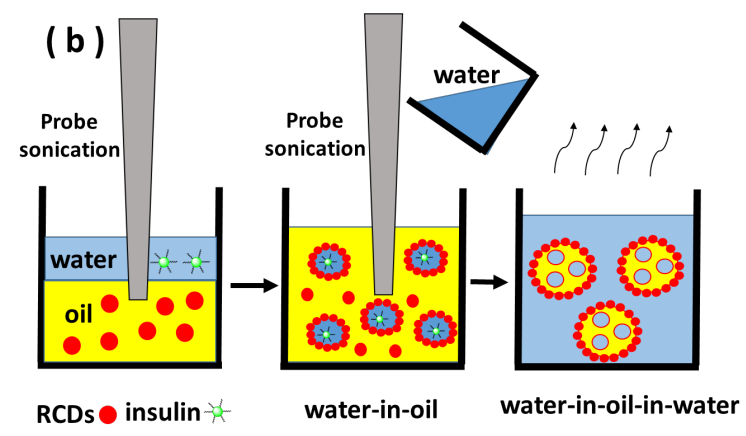

Scheme 1. (a) Oil-in-water single Pickering emulsion system. (b) waterin-oil-in-water double Pickering emulsion system.

Surface properties of RCDs are very important for the stability 5 of emulsion droplets. Because P-phenylenediamine was used as starting materials, the surface of RCDs was covered by pyridine$\mathrm{N}$, pyrrole-N structures and amine groups, which is helpful for them to be well dispersed in both water and oil phase. The size of RCDs was around $10 \mathrm{~nm}$ as shown in transmission electron 10 microscopy (TEM) image (Fig. 1a). The FT-IR technique was employed to identify the functional groups on the surface of RCDs (Fig. 1b). The intense and sharp peaks in the 3200-3400 $\mathrm{cm}^{-1}$ region belonged to $\mathrm{N}-\mathrm{H}$ stretching of aromatic amines. In addition, $\mathrm{N}-\mathrm{H}$ bend at $1625 \mathrm{~cm}^{-1}$ revealed the presence of primary 15 amine groups, ensuring the presence of hydrophilic groups on the surface. The C-N stretch appeared at $1260 \mathrm{~cm}^{-1}$ rather than at lower wavenumbers because it was an aromatic amine, which to certain extent, rendered RCDs hydrophobic. The characterization demonstrated that the synthesized RCDs had both hydrophilic 20 and hydrophobic properties, which allowed RCDs to be well dispersed in both water and DCM. Therefore, RCDs could help to stablize both $\mathrm{O} / \mathrm{W}$ and $\mathrm{W} / \mathrm{O} / \mathrm{W}$ emulsion.
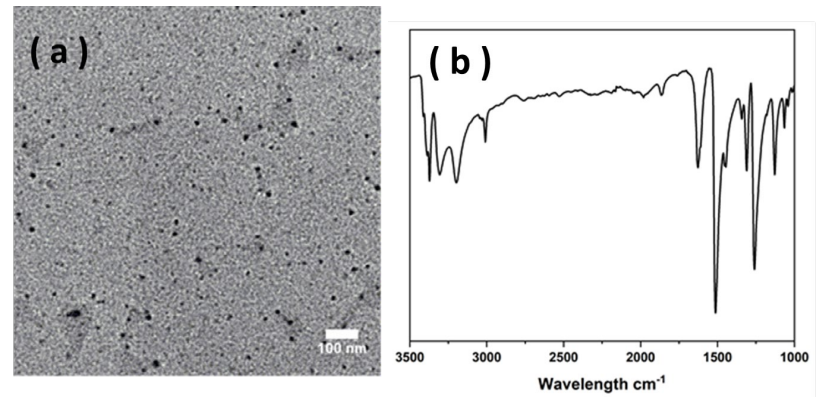

Fig. 1 (a) TEM image of RCDs. (b) FT-IR of RCDs.

25 By using RCDs as the stabilizer, we prepared oil-in-water $(\mathrm{O} / \mathrm{W})$ Pickering emulsion droplets to encapsulate hydrophobic drug Azithromycin (AZI) (scheme 1a), and water-in-oil-in-water (W/O/W) Pickering emulsion droplets to encapsulate hydrophilic drug insulin (scheme 1b). Dichloromethane (DCM), a widely 30 used organic solvent, was used as oil phase to dissolve PLGA and hydrophobic drug (scheme 1a). To prepare the PLGA nanoparticles loaded with hydrophobic drug from single Pickering emulsion, DCM containing the AZI and PLGA was added to the aqueous phase containing RCDs. This mixture was 35 sonicated by using a probe sonicator to give a stable Pickering emulsion. The size of these droplets could be controlled by varying probe sonication amplitude and time. After most DCM evaporated, PLGA nanoparticles were precipitated. Then we used an evaporator to remove the residual DCM in PLGA 40 nanoparticles.

To prepare the PLGA DDS loaded with insulin, $\mathrm{W} / \mathrm{O} / \mathrm{W}$ double emulsion was applied (scheme 1b). RCDs were firstly dispersed in oil phase instead of water phase. The aqueous phase containing insulin was added into the oil phase containing RCDs 45 ad PLGA. The mixutre was sonicated to prepare the first emulsion. Subsequently, the aquesous phase containing RCDs was added to the resulted first emulsion under the sonication to prepare the $\mathrm{W} / \mathrm{O} / \mathrm{W}$ emulsion. Due to good dispersion performance in both water and oil phase, RCDs can effectively 50 stablize the first emulsion and second emulsion. Other procedures were similar to the single emuslion system.

Dynamic light scattering (DLS) was used to determine the size and the zeta potential of the resulted PLGA nanoparticles (Fig. S2, ESI). The average sizes of the PLGA nanoparticles prepared 55 using single emulsion and double emulsion methods were observed to be $161 \mathrm{~nm}$ and $194 \mathrm{~nm}$ with narrow size distribution (PDI), respectively. This was further supported by the TEM images (Fig. 2a and Fig. 2b), which showed both PLGA nanoparticles were spherical with the diameter of 100-200 nm. In 60 addition, the zeta potentials were measured to be $13.2 \mathrm{mv}$ and $12.6 \mathrm{mv}$, respectively.

NIR-responsive DDS systems is usually resulted from photothermal effect, where NIR irradiation leads to the temperature increase of nanocarriers. Herein, the photothermal 65 properties of the PLGA nanoparticles were determined with 808 nm laser irradiation at different power densities. As shown in Fig. 2c, for PLGA from single emulsion, the temperature of solution increased by $6.9,10.3$, and $13.4{ }^{\circ} \mathrm{C}$ after irradiation for $10 \mathrm{~min}$ at power densities of $1.0,2.0$, and $3 \mathrm{~W} \mathrm{~cm}^{-2}$, respectively. 70 Meanwhile, for PLGA from double emulsion, the temperature of solution increased by 7.6, 16.3, and $18.4{ }^{\circ} \mathrm{C}$ after irradiation for $10 \mathrm{~min}$ at power densities of $1.0,2.0$, and $3 \mathrm{~W} \mathrm{~cm}^{-2}$, respectively, as shown in Fig. 2d. The results confirmed the successful encapsulation of RCDs inside the PLGA nanoparticles and good 75 photothermal effect of the RCDs. It was worth noting that the PLGA nanoparticles prepared by the double emulsion method showed a higher photothermal effect. This could be due to that fact that more RCDs were encapsulated in double emulsion than that in PLGA single emulsion. To further prove the photothermal 80 effect of RCDs, we also invested the temperature increase of PLGA without RCDs, RCDs and PLGA with RCDs under laser irradiation. Fig. S3 (ESI) showed that there was big differences in the temperature increase with and without RCDs.

The drug loading (DL), drug encapsulation efficacy (EE) as 85 well as the drug release profile of the resulted PLGA nanoparticles were also investigated. Azithromycin is a broadspectrum antibiotic with substantial antibacterial activities against Gram-positive and Gram negative pathogens. AZI also exhibits the anti-biofilm activity. ${ }^{25}$ The DD and EE of AZI-loaded PLGA 90 nanoparticles were found to be $4.1 \%$ and $15.4 \%$, respectively (Table S1, ESI). The results were comparable to other reported PLGA DDS. ${ }^{26}$ 

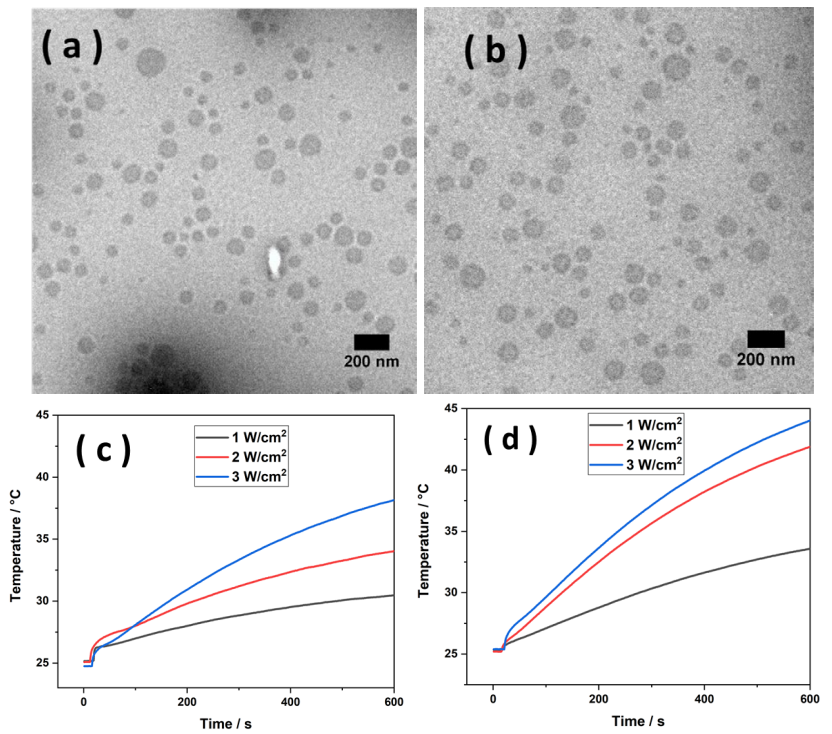

Fig. 2 TEM of PLGA nanoparticles from single emulsion (a) and double emulsion; (b). Photothermal heating curves of the PLGA nanoparticles

5 solution $(1 \mathrm{mg} / \mathrm{ml})$ from single emulsion (c) and double emulsion (d) under $808 \mathrm{~nm}$ laser irradiation at different power densities.

The release of encapsulated drugs from PLGA nanoparticles at both $25^{\circ} \mathrm{C}$ and $37^{\circ} \mathrm{C}$ was evaluated by measuring the amount of released drug with HPLC. As shown in Fig. 3a, around $70 \%$ of 10 the drug was released during the first $8 \mathrm{~h}$, which demonstrated a fast drug release profile. It was also found that the release curves were almost the same at $25{ }^{\circ} \mathrm{C}$ and $37{ }^{\circ} \mathrm{C}$. The finding was interesting, and it suggested that the AZI molecules were mainly located at the surface of the RCD-PLGA nanoparticles. This 15 might be due to the strong interactions between the primary amine of RCDs and tertiary amine groups of AZI. Consequently, AZI was mainly loaded around RCDs rather than in the PLGA matrix. The unique feature could benefit for combination therapy (i.e. co-delivery of multiple drugs for the synergistic therapeutic 20 effects) because it enables the definitive co-delivery of a correct ratio of drug combination in the same nanoparticle and temporally controlled their release by precisely manipulating the location of individual drug in the nanoparticles. ${ }^{27-29}$ For example, the rapid release of antibiotics from CQDs layer can

25 lead to the therapeutic level of drug at the site of action in a short time, consequently, resulting in the bactericidal effect. Meanwhile, the sustained release of antibiotics from PLGA matrix can maintain the therapeutic concentrations at the site of action for a long period.

30 Insulin is a protein composed of 51 amino acids, and has a molecular mass of $5.8 \mathrm{KDa}$. It regulates the metabolism of carbohydrates, and is mainly used to treat diabet patients.To achieve optimal therapeutic effect, a sustained release profile is required. In addition, stimuli-triggered release is considered as an

35 advantage as the release can be fine-tuned to react to sudden change of gluocose level (e.g., after meals). As listed in Table S1 (ESI), high EE was achieved for the hydrophilic drug, which was $46.8 \%$. It was speculated that with the double emulsion structure, majority of insulin was able to be encapsulated inside the PLGA

40 nanoparticles. The drug release profile was shown in Fig. 3b. The release rate of insulin was much higher at $37^{\circ} \mathrm{C}$ than at $25^{\circ} \mathrm{C}$.
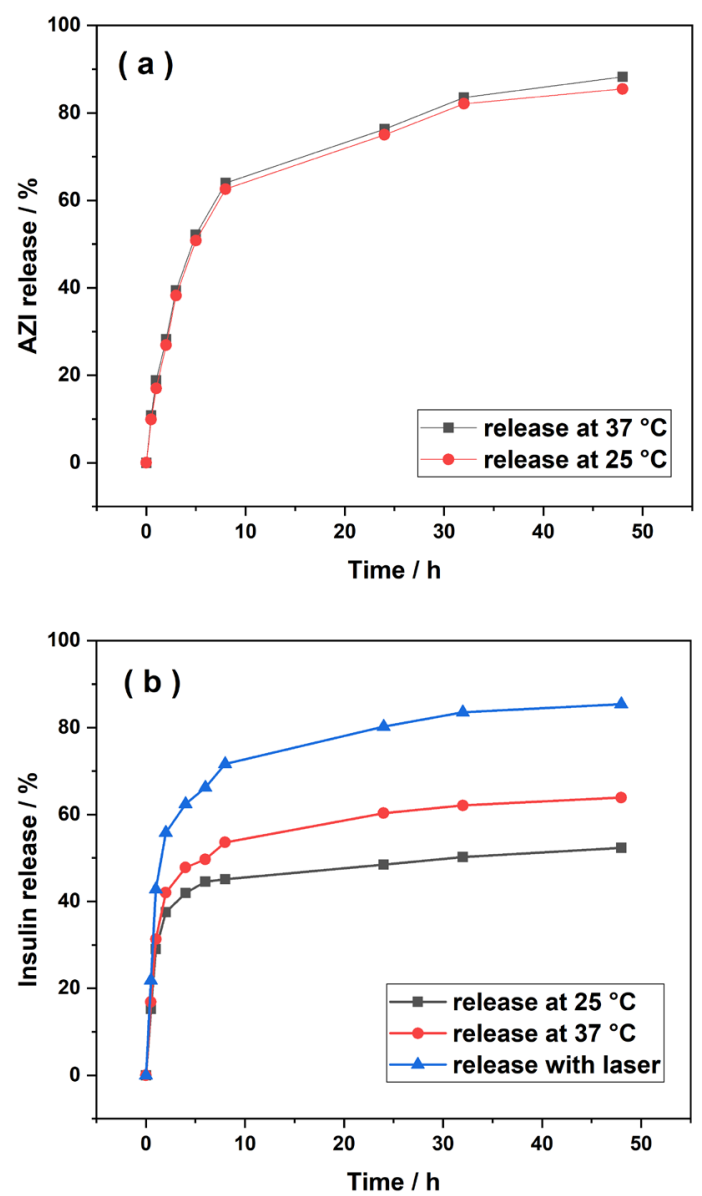

45 Fig. 3 (a) Release of AZI from PLGA nanoparticles at $25^{\circ} \mathrm{C}$ and $37^{\circ} \mathrm{C}$. (b) Release of insulin from PLGA nanoparticles at $25{ }^{\circ} \mathrm{C}, 37{ }^{\circ} \mathrm{C}$ and with laser irradiation.

We further performed experiments to investigate whether RCD-PLGA DDS could enhance the release rate of insulin under ${ }_{50}$ the $808 \mathrm{~nm}$ laser irradiation. The dialysis device was irradiated for $10 \mathrm{~min}$ at power densities of $3 \mathrm{~W} \mathrm{~cm}^{-2}$ at every hour, then put back in the water bath $\left(37^{\circ} \mathrm{C}\right)$. As shown in Fig. 3 b, there was an obvious increase in the release rate after laser irradiation compared with the release at $37{ }^{\circ} \mathrm{C}$ without light. The results ${ }_{55}$ proved that the RCDs had strong absorption in NIR range and could effiently covert the light energy into heat. The increase in temperature further prompted the disruption of the structure of PLGA nanoparticles, thereby enhancing the insulin release. The NIR-responsive PLGA nanocarriers is of special interest for ${ }_{60}$ drugs such as insulin, as the release speed and amound could be precisely tuned remotely.

In conclusion, we demonstrated a new RCD-stablized Pickering emulsion method by which PLGA nanoparticles could be prepared without using any surfactant. Our findings suggested ${ }_{65}$ that the use of solid particles as a stabilizer avoided residual surfactant and allowed multi-functionalization of PLGA nanoparticles for controlled drug release. Further, other solid particles such as magnetic particles or quantum dots with different functional groups, could also be applied to stabilize the 70 emulsion. Thus, the methods described here represented a unique platform for effective delivery of drugs with multiple functions. 
This work was financially supported by the Villum Fonden, Denmark, Project No. 13153.

\section{Conflicts of interest}

${ }_{5}$ There are no conflicts to declare.

\section{Notes and references}

${ }^{a}$ Department of Health technology, Technical University of Denmark, Denmark.E-mail:yi.sun@dtu.dk;

$10{ }^{b}$ Department of Pharmacy, University of Copenhagen, Copenhagen,

Denmark.E-mail:feng.wan@sund.ku.dk

1 S. Dhar, F. X. Gu, R. Langer, O. C. Farokhzad and S. J. Lippard, Proc. Natl. Acad. Sci., 2008, 105, 17356-17361.

152 A. J. Mieszawska, A. Gianella, D. P. Cormode, Y. Zhao, A. Meijerink, R. Langer, O. C. Farokhzad, Z. A. Fayad and W. J. M. Mulder, Chem. Commun., 2012, 48, 5835-5837.

3 W. Bao, J. Zhou, J. Luo and D. Wu, J. Microencapsul., 2006, 23, 471-479.

204 Zhai, Biomaterials, 2000, 21, 2475-2490.

5 M. Allahyari and E. Mohit, Hum. Vaccines Immunother., 2016, 12, 806-828.

6 F. Danhier, E. Ansorena, J. M. Silva, R. Coco, A. Le Breton and V. Préat, J. Control. Release, 2012, 161, 505-522.

257 J. U. Menon, S. Kona, A. S. Wadajkar, F. Desai, A. Vadla and K. T. Nguyen, J. Biomed. Mater. Res. - Part A, 2012, 100 A, 1998-2005.

K. Nazila, B. Yameen, J. Wu§ and O. C. Farokhzad, Chem Rev., 2016, 116, 2602-2663.

309 E. Fazio, A. Scala, S. Grimato, A. Ridolfo, G. Grassi and F. Neri, J. Mater. Chem. B, 2015, 3, 9023-9032.

10 I. Tomic, A. Vidis-Millward, M. Mueller-Zsigmondy and J. M. Cardot, Int. J. Pharm., 2016, 505, 42-51.

11 E. Swider, O. Koshkina, J. Tel, L. J. Cruz, I. J. M. de Vries and

35 M. Srinivas, Acta Biomater., 2018, 73, 38-51.

12 G. Manley, 2013, 71, 233-236.

13 S. Mura, J. Nicolas and P. Couvreur, Nat. Mater., 2013, 12, 991-1003.

14 S. Goenka, V. Sant and S. Sant, J. Control. Release, 2014, 173, $40 \quad 75-88$.

15 J. He, X. Huang, Y. C. Li, Y. Liu, T. Babu, M. A. Aronova, S. Wang, Z. Lu, X. Chen and Z. Nie, J. Am. Chem. Soc., 2013, 135, 7974-7984.

16 X. Liu, Q. Ren, F. Fu, R. Zou, Q. Wang, G. Xin, Z. Xiao, X. 45 Huang, Q. Liu and J. Hu, Dalt. Trans., 2015, 44, 10343-10351.

17 Y. Yang, Z. Fang, X. Chen, W. Zhang, Y. Xie, Y. Chen, Z. Liu and W. Yuan, Front. Pharmacol., 2017, 8, 287.

18 X. Shen, J. Svensson Bonde, T. Kamra, L. Bülow, J. C. Leo, D. Linke and L. Ye, Angew. Chemie - Int. Ed., 2014, 53, 10687-

50 10690 .

19 Y. Zhou, Z. Peng, E. S. Seven and R. M. Leblanc, J. Control. Release, 2018, 270, 290-303.

20
Bashammakh, M. S. El-Shahawi and R. M. Leblanc, J. Mater.
55

60 Chem. B, 2016, 4, 7398-7405.

N. Dimitrova, J. R. Zamudio, R. M. Jong, D. Soukup, R. Resnick, K. Sarma, A. J. Ward, A. Raj, J. Lee, P. A. Sharp and T. Jacks, PLoS One, 2017, 32, 736-740.

Y. Liu, L. Zhou, Y. Li, R. Deng and H. Zhang, Nanoscale, 2017, 9, 491-496.

S. Y. Lim, W. Shen and Z. Gao, Chem. Soc. Rev., 2015, 44, 362-81.

T. Zhou, J. Ashley, X. Feng and Y. Sun, Talanta, 2018, 190, 443-449.

S. Favre-Bonté, T. Köhler and C. Van Delden, J. Antimicrob. Chemother., 2003, 52, 598-604.

F. Teng, P. Deng, Z. Song, F. Zhou, R. Feng and N. Liu, J. Colloid Interface Sci., 2017, 496, 16-25.

N. Kolishetti, S. Dhar, P. M. Valencia, L. Q. Lin, R. Karnik, S. J. Lippard, R. Langer and O. C. Farokhzad, Proc. Natl. Acad. Sci., 2010, 107, 17939-17944.

S. Sengupta, D. Eavarone, I. Capila, G. Zhao, N. Watson, T. Kiziltepe and R. Sasisekharan, Nature, 2005, 436, 568-572.

X. Duan, J. Xiao, Q. Yin, Z. Zhang, H. Yu, S. Mao and Y. Li, ACS Nano, 2013, 7, 5858-5869. 